\title{
Effect of Pelvic Rocking Exercise Using the Birth Ball on Fetal Lie, Attitude, and Presentation
}

\author{
Supriatiningsih $^{1}{ }^{\mathbb{D}}$, Herlina $^{2}$, Lusia Asih Wulandari ${ }^{3}$, Sri Nowo Retno ${ }^{3}$, Mohammad Kanedi $^{*}{ }^{(\mathbb{D}}$
}

\begin{abstract}
Objectives: For decades, scholars have debated the benefits of exercise during pregnancy. Birthing ball exercise is the latest among the antenatal exercises which pregnant women commonly perform in Indonesia. Therefore, the current study aimed to investigate whether pelvic rocking exercise using the birth ball is effective in correcting the fetal lie, presentation, and attitude in the late third trimester of pregnancy.

Materials and Methods: To this end, pregnant women $(n=114)$ enjoying the inclusion criteria were randomly divided into intervention (who were assigned to perform pelvic rocking using the birth ball) and control (without exercise) groups. Fetal lie, attitude, and presentation before and after the trials were determined in both groups by performing the abdominal palpation of Leopold's maneuver.

Results: Based on the results, the intervention group showed a higher proportion of fetus with flexed attitude $(P<0.001)$ as compared to the control group. In addition, $49.1 \%$ of women in the intervention group indicated longitudinal lie compared to $29.8 \%$ of those in the control groups $(P<0.001)$. Finally, 56 out of 57 women in the intervention group demonstrated head presentation whereas only 45 out of 57 women in the control group showed the same presentation $(P<0.01)$.

Conclusions: Overall, it is suggested that pelvic rocking exercises using the birth balls are useful for maintaining lies, fetal attitudes, and presentations and thus it is worth recommending for pregnant women.

Keywords: Pregnancy exercise, Pelvic rocking, Birthing ball, Fetal presentation
\end{abstract}

\section{Introduction}

Maternal mortality ratio (MMR) in Indonesia is the highest among countries in the South Eastern Asian Region (1) and prolonged labor is among the factors which are contributed to such a high MMR (2). The 2012 Indonesia Demographic Health Survey findings revealed that among 14782 birth numbers, $34.7 \%$ of the mothers experience prolonged labor, and at least $0.8 \%$ of the cases end with maternal deaths (3). In addition, compared to the prevalence of prolonged labor on average (one-fifth of women), the prevalence of the cases in Indonesia is higher (4).

Prolonged labor often causes serious consequences for both mother and infant. For mothers, it can lead to maternal exhaustion and dehydration, along with severe postpartum hemorrhage (5) while in infants, it can decrease the score of Apgar (i.e., appearance, pulse, grimace, activity, and respiration) scale whereas increasing the asphyxia incidence (6). Considering the adverse consequences, taking into account the treatment and management of prolonged labor are of great importance (7).

Several factors affect labor and delivery, including fetal size, the size and shape of maternal pelvis, uterine contraction forces, maternal position, and maternal psyche response (8). Reports from Indonesia show that passenger (fetus) is the most frequent among these prolonged laborrelated factors. A study performed in Kalimantan Selatan (South Borneo) during 1995-1996 also indicated that the passenger (64\%) was the most important factor which was related to 72 prolonged labor cases (9). The findings of another study conducted in Lampung province revealed that among the prolonged labor cases, $39.2 \%$ were related to fetal malposition and presentation and $37.2 \%$ belonged to fetal macrosomia (10).

With regard to the fetal malposition and malpresentation, the question arises regarding whether there is any method that birthing mothers and/or care providers can employ to correct the abnormality. Among others, the use of antenatal exercises is present for facilitating the fetus to rotate from the occiput posterior position to a favorable occiput anterior presentation (11). Maternal postural techniques are also suggested for encouraging and attaining the best cephalic version of the baby's head to enter maternal pelvis (12). The overall benefits of pregnancy exercise include shorter labor, less preterm labor, less complications, and decreased hospital stay (13).

In this regard, birthing ball exercise is considered as the most recent method among the antenatal exercises which pregnant women prevalently perform in Indonesia. So far,

Received 13 March 2018, Accepted 2 November 2018, Available online 7 January 2019

${ }^{1}$ Department of Midwifery, MoH Health Polytechnic of Tanjung Karang, Lampung, Indonesia. ${ }^{2}$ Azizah Hospital, Kota Metro, Lampung, Indonesia. ${ }^{3}$ Midwifery Academy of Patriot Bangsa Husada, Lampung Tengah, Lampung, Indonesia. ${ }^{4}$ Department of Biology, Faculty of Mathematics and

Sciences, University of Lampung, Bandar Lampung, Indonesia.

*Corresponding Author: Mohammad Kanedi, Email: wegayendi@yahoo.com 
several studies have reported the benefits of pregnancy exercise using a birthing ball, including managing pain mainly the back pain, as well as decreasing stress and anxiety levels, the pethidine usage in labour wards, and cesarean section rate (14-16). Furthermore, the women in labor not only can manage to cope with the labor pain and progress but also attain self-control and more satisfactory birthing experience when the birth ball is used to perform pelvic rocking (17).

Further, the exercise may allegedly affect fetalpositioning in utero if pelvic rocking exercise with a birth ball is considered useful for reducing the pain, increasing the labor progress, and making the birthing experience more satisfactory. Given the above-mentioned explanations, the present study sought to evaluate whether the pelvic rocking exercise using the birth ball contributes to correcting the fetal position from transverse or oblique to longitudinal, the fetal presentation from the breech or the shoulder to head, and fetal attitude from the deflexed to flexed posture in the late third trimester of pregnancy.

\section{Materials and Methods}

Participants and Study Design

The research targeted pregnant females living in the territory of three community health centers (Pusat Kesehatan Masyarakat) in the district of Kota Metro, Lampung, namely, Yosomulyo, Margorejo, and dan Karangrejo. A quota sampling technique was applied to select the research subjects who had the following inclusion criteria:

1. Showing singleton pregnancy;

2. Being at or more than 29 weeks of gestation;

3. Willing to sign the informed consent;

4. Willing to perform pelvic rocking;

5. Representing no sign of pelvic disorder;

6. Having no bleeding during pregnancy;

7. Demonstrating no fetal malposition.

Otherwise, the subjects were considered ineligible. Finally, 114 pregnant women were included in the study and were randomly classified into intervention (assigned to perform pelvic rocking using the birth ball) and control (without exercise) groups. The baseline of fetal position in both groups was determined by performing the abdominal palpation of Leopold's maneuver immediately upon receiving the informed consent.

\section{Interventions}

The employed birthing balls were the Kettler Gym Ball with a diameter of $65 \mathrm{~cm}$. Five well-trained midwives provided the instructions to mothers regarding pelvic rocking exercises using the birth ball. The exercises included 5 steps as follows:

- $\quad$ Sitting straddle on the ball;

- Rocking the pelvis forward and backward with shoulder still 4 times;

- Rocking the pelvis to the left and right side with shoulder still 4 times;

- Rotating the hips clockwise then anti-clockwise 4 times;

- $\quad$ Swaying the hips in a figure-eight pattern four times. All women in the intervention group performed the exercises weekly for 3 weeks and then, by using a questionnaire, they were asked to report whether they correctly performed the exercises. At the end of the program, mothers of both groups were evaluated for the fetal position using the abdominal palpation of Leopold's maneuver.

\section{Fetal Assessment}

The four performed Leopold's maneuvers in the abdominal palpation were as follows:

The first and the second maneuvers were performed to determine the presenting part at the fundus and the fetal back, respectively. Moreover, the third and the fourth maneuvers were performed to identify the position and mobility of the presenting part and the fetal descent, respectively. The evaluated variables were fetal lie, presentation, and attitude. The fetal lie is either longitudinal, transverse, or oblique and fetal presentation is distinguished into the head, breech, or shoulder whereas fetal attitude is either of flexed or deflexed posture.

\section{Data Analysis}

Both descriptive and inferential statistics from SPSS software, version 22.0 were applied in the data analysis. The descriptive statistics were used to depict the general characteristic of the research subjects while inferential statistics (the chi-square test) were performed to compare the subjects with and without pelvic rocking exercise. The limit of statistical significance was $P<0.05$.

\section{Results}

Characteristics of the Subjects

Characteristics including age, education, gravidity, and the fetal position of both intervention and control groups are presented in Table 1 . With regard to age, the majority of women of both groups (57.9\% and 59.6\% in intervention and control groups, respectively) aged over 31 years. As regards the education level, there was a difference between the two groups. Similarly, most women in the intervention group (62.3\%) had upper secondary education while those in the control group had mostly (50.9\%) primary education. In terms of gravidity, the majority of women in both groups $(70.2 \%$ and $59.6 \%$ in intervention and control groups, respectively) had multigravida (two or more pregnancies). Furthermore, based on the pretrial assessments of the fetal position (baseline), it was ascertained that the fetal attitude, lie, and presentation were normal in both groups. Additionally, 70.3\% and 71.9\% of patients in intervention and control groups were flexed in terms of the fetal attitude, respectively. Incidentally, both groups showed the same proportion of fetal lie including 
Table 1. General and Baseline Characteristics of Intervention and Control Groups

\begin{tabular}{|c|c|c|c|c|}
\hline \multirow{2}{*}{ Characteristics } & \multicolumn{2}{|c|}{ Intervention } & \multicolumn{2}{|c|}{ Control } \\
\hline & No. & $\%$ & No. & $\%$ \\
\hline Age & 57 & 100 & 57 & 100 \\
\hline$\leq 20$ years & 1 & 1.8 & 6 & 10.5 \\
\hline $21-30$ years & 23 & 40.4 & 17 & 29.8 \\
\hline$\geq 31$ years & 33 & 57.9 & 34 & 59.6 \\
\hline Education & 57 & 100 & 57 & 100 \\
\hline Primary & 17 & 29.8 & 29 & 50.9 \\
\hline Secondary & 31 & 54.5 & 18 & 31.6 \\
\hline Higher education & 9 & 15.8 & 10 & 17.5 \\
\hline Gravidity & 57 & 100 & 57 & 100 \\
\hline Primigravida & 14 & 24.6 & 10 & 17.5 \\
\hline Multigravida & 40 & 70.2 & 34 & 59.6 \\
\hline Grande multigravida & 3 & 5.3 & 13 & 22.8 \\
\hline Fetal attitude & 57 & 100 & 57 & 100 \\
\hline Flexed & 40 & 70.2 & 41 & 71.9 \\
\hline Deflexed & 17 & 29.8 & 16 & 28.1 \\
\hline Fetal lie & 57 & 100 & 57 & 100 \\
\hline Longitudinal & 33 & 57.8 & 33 & 57.8 \\
\hline Oblique & 22 & 38.6 & 22 & 38.6 \\
\hline Transverse & 2 & 3.6 & 2 & 3.6 \\
\hline Fetal presentation & 57 & 100 & 57 & 100 \\
\hline Head & 50 & 87.8 & 45 & 78.9 \\
\hline Breech & 6 & 10.6 & 3 & 5.3 \\
\hline Shoulder & 1 & 1.8 & 9 & 15.8 \\
\hline
\end{tabular}

the longitudinal, oblique, and transverse lies of $57.8 \%$, $38.6 \%$, and $3.6 \%$, respectively. Eventually, respecting fetal presentation, $87.8 \%$ of women in the intervention group and $78.9 \%$ of them in the control group indicated a normal presentation (head presentation).

\section{Trial Effects}

Tables 2, 3, and 4 provide the fetal attitude, lie, and presentation of the intervention and control groups after three-week clinical trials, respectively. As shown in Table 1 , the pelvic rocking exercise using the birth ball (50\%) significantly $(P<0.001)$ leads to the flexed attitude of the fetus in comparison to the control group (35.1\%).

Based on the data and statistical test results in Table 3, the pelvic rocking also showed a significant contribution to correcting the fetal lie so that $49.1 \%$ of women in the intervention group indicated longitudinal lie compared to $29.8 \%$ of those in the control group $(P<0.001)$.

Furthermore, the data and statistical test results in Table 4 represent that pelvic rocking exercises with the birth ball play a role in normalizing the fetal presentations. In the intervention group, 56 out of 57 subjects demonstrated the head presentation whereas only 45 out of 57 of them in the control group that indicated the head presentation $(P<0.01)$.

\section{Discussion}

Based on the data presented in Table 1, the participant characteristics of both intervention and control groups were balanced except for the level of education. The secondary or higher education levels $(70.3 \%)$ of women in the intervention group is a probable explanation for their willingness to follow the pelvic rocking. As was scientifically suggested, further education leads to more knowledge, capability, and awareness of individuals regarding adopting a healthy lifestyle and maintaining their physical health including performing exercises (18).

Considering the data in Tables 2, 3, and 4, pelvic rocking with a birth ball should be emphasized and recommended in antenatal care during pregnancy. Nevertheless, the controversy about the benefits of pregnancy exercises on prolonged labor is not inevitable. As it is known, during the 1960s, there has been a debate about the value of exercise during labor. Although it is doubtful that exercise during pregnancy is extremely beneficial in shortening the birth process, it can reduce the structural burden experienced by the mother in pregnancy and labor in addition to reducing the back pain and improving the abdominal posture and pelvis muscle. Pelvic shaking exercises alone are considered useless in improving the pelvic capacity, though they are only beneficial in reducing the back

Table 2. Fetal Attitude of Intervention and Control Groups

\begin{tabular}{|c|c|c|c|c|c|}
\hline \multirow{3}{*}{ Trials } & \multirow{3}{*}{$\begin{array}{l}\text { Total } \\
\text { No. (\%) }\end{array}$} & \multicolumn{4}{|c|}{ Fetal Attitude } \\
\hline & & \multicolumn{2}{|r|}{ Flexed } & \multicolumn{2}{|c|}{ Deflexed } \\
\hline & & No. & $\%$ & No. & $\%$ \\
\hline Intervention & $57(50)$ & 57 & 50.0 & 0 & 0.0 \\
\hline Control & $57(50)$ & 40 & 35.1 & 17 & 14.9 \\
\hline Total & $114(100)$ & 97 & 85.1 & 17 & 14.9 \\
\hline \multicolumn{6}{|c|}{ Chi-Square Tests } \\
\hline & Value & df & Asymp. Sig. (2-sided) & Exact Sig. (2-sided) & Exact Sig. (1-sided) \\
\hline Pearson Chi-square & $19.979^{a}$ & 1 & 0.000 & \multirow{5}{*}{0.000} & \multirow[t]{5}{*}{0.000} \\
\hline Continuity correction ${ }^{b}$ & 17.698 & 1 & 0.000 & & \\
\hline Likelihood ratio & 26.562 & 1 & 0.000 & & \\
\hline Linear-by-linear association & 19.804 & 1 & 0.000 & & \\
\hline No. of valid cases ${ }^{b}$ & 114 & & & & \\
\hline
\end{tabular}

a Zero cells $(0 \%)$ have an expected count less than five and the minimum expected count is 8.50 ; ${ }^{\mathrm{b}} \mathrm{Computed}$ only for a $2 \times 2$ table. 
Table 3. Fetal Lie of Intervention and Control Groups

\begin{tabular}{|c|c|c|c|c|c|c|c|c|}
\hline \multirow{3}{*}{ Trials } & \multirow{2}{*}{\multicolumn{2}{|c|}{ Total }} & \multicolumn{6}{|c|}{ Fetal Lie } \\
\hline & & & \multicolumn{2}{|c|}{ Longitudinal } & \multicolumn{2}{|c|}{ Oblique } & \multicolumn{2}{|c|}{ Transverse } \\
\hline & No. & $\%$ & No. & $\%$ & No. & $\%$ & No. & $\%$ \\
\hline Intervention & 57 & 50 & 56 & 49.1 & 0 & 0 & 1 & 0.9 \\
\hline Control & 57 & 50 & 34 & 29.8 & 22 & 19.3 & 1 & 0.9 \\
\hline Total & 114 & 100 & 90 & 78.9 & 22 & 19.3 & 2 & 1.8 \\
\hline \multicolumn{9}{|c|}{ Chi-Square Tests } \\
\hline & Value & df & Asymp & (2-sided) & \multicolumn{2}{|c|}{ Exact Sig. (2-sided) } & \multicolumn{2}{|c|}{ Exact Sig. (1-sided) } \\
\hline Pearson chi-square & $27.378^{a}$ & 2 & \multicolumn{2}{|c|}{0.000} & \multicolumn{2}{|c|}{0.000} & \multirow{3}{*}{\multicolumn{2}{|c|}{0.000}} \\
\hline Likelihood ratio & 35.931 & 2 & \multicolumn{2}{|c|}{0.000} & \multicolumn{2}{|c|}{0.000} & & \\
\hline Fishers exact test & 32.570 & & & & \multicolumn{2}{|c|}{0.000} & & \\
\hline Linear-by-linear association & $19.931^{\mathrm{b}}$ & 1 & \multicolumn{2}{|c|}{0.000} & \multicolumn{2}{|c|}{0.000} & & \\
\hline No. of valid cases & 114 & & & & & & & \\
\hline
\end{tabular}

a Two cells (33.3\%) have an expected count less than five and the minimum expected count is 1.00 ; ${ }^{b}$ The standardized statistic is 4.464 .

Table 4. Fetal Presentation of Intervention and Control Groups

\begin{tabular}{|c|c|c|c|c|c|c|c|c|}
\hline \multirow{3}{*}{ Trials } & \multirow{2}{*}{\multicolumn{2}{|c|}{ Total }} & \multicolumn{6}{|c|}{ Fetal Presentation } \\
\hline & & & \multicolumn{2}{|c|}{ Head } & \multicolumn{2}{|c|}{ Breech } & \multicolumn{2}{|c|}{ Shoulder } \\
\hline & No. & $\%$ & No. & $\%$ & No. & $\%$ & No. & $\%$ \\
\hline Intervention & 57 & 50 & 56 & 49.1 & 0 & 0 & 1 & 0.9 \\
\hline Control & 57 & 50 & 45 & 39.5 & 4 & 3.5 & 8 & 7.0 \\
\hline Total & 114 & 100 & 101 & 88.6 & 4 & 3.5 & 9 & 7.9 \\
\hline \multicolumn{9}{|c|}{ Chi-Square Tests } \\
\hline & Value & df & Asymp & -sided) & \multicolumn{2}{|c|}{ Exact Sig. (2-sided) } & \multicolumn{2}{|c|}{ Exact Sig. (1-sided) } \\
\hline Pearson Chi-square & $10.642^{\mathrm{a}}$ & 2 & \multicolumn{2}{|c|}{0.005} & \multicolumn{2}{|c|}{0.002} & \multirow{3}{*}{\multicolumn{2}{|c|}{0.001}} \\
\hline Likelihood ratio & 12.943 & \multirow[t]{2}{*}{2} & \multicolumn{2}{|c|}{0.002} & \multicolumn{2}{|c|}{0.004} & & \\
\hline Fishers exact test & 10.330 & & & & \multicolumn{2}{|c|}{0.004} & & \\
\hline Linear-by-linear association & $8.982^{\mathrm{b}}$ & 1 & \multicolumn{2}{|c|}{0.003} & \multicolumn{2}{|c|}{0.003} & & \\
\hline No. of valid cases & 114 & & & & & & & \\
\hline
\end{tabular}

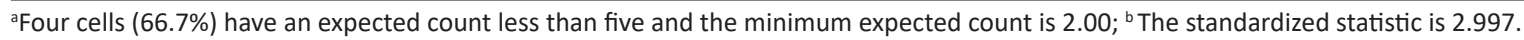

pain (19).

Later and toward the third millennium, the benefits of exercise during pregnancy received attention once more. Some of the benefits of pregnancy exercise are as follows:

- Minimizing the weight gain by reducing body fat accumulation;

- Minimizing backache;

- Reducing pregnancy discomfort;

- Maximizing the ability to manage breathing and relaxation;

- Reducing stress and increasing the self-confidence;

- Minimizing labor complications;

- Accelerating postpartum recovery.

Based on the study results of a study on the efficacy of pregnancy exercises, body movement in the exercise can enhance cardiovascular capacity and increase muscle strength, elasticity, and extensibility (20), which is in line with the results of the current study.

In addition, based on the findings of another study regarding testing the efficacy of moxibustion as the traditional Chinese medicine in labor, the improved fetal positions were suspected to be associated with uterine muscle contractions (21). The practice of moxibustion is thought to encourage the placenta to produce more estrogen, enhance the production of prostaglandin that affects the uterus contraction leading to a higher probability of optimal fetal positioning, and finally, facilitate the fetal movements (22).

Despite its long history of invention, the use of the birth ball, originally called the Swiss ball, advocated in pregnancy exercise. The findings of the current study confirm the benefits of exercise with the birth ball during pregnancy, which corroborates with the findings of many previous studies. The pelvic rocking exercise and birthing ball were revealed to be useful in shortening the labor process and empowering mothers during the labor in addition to be effective in managing the lower back pain during pregnancy $(23,24)$. Likewise, the physical exercises performed during pregnancy between the second and third trimesters are reported to be beneficial in reducing the labor duration of the first stage and the possibility of cesarean operation (25).

The recent reviews of prenatal care practices show that physical activity during pregnancy is still highly promoted regardless of the type of exercise since it is of great benefit to maternal and infant health during the peri and 
postnatal period. (26). Further, physical activities during pregnancy play a role in assisting the mothers' locomotor system in adapting to mother's biomechanics that might arise from weight gain during pregnancy (27). Based on the reports, aerobic exercise performed 3-4 times a week for 35-90 minutes significantly associates with a lower frequency of cesarean operation and a high incidence of vaginal births (28). Thus, these findings provide a basis for assuming that exercise during pregnancy is useful in facilitating labor.

\section{Conclusions}

In general, the present study applied the pelvic rocking exercise using the birth ball based on the abdominal palpation using four Leopold's maneuvers and the results confirmed the success of such exercise in maintaining and promoting normal lies, fetal attitudes, and presentations. Thus, pelvic rocking exercises by the birth ball are highly recommended for pregnant women.

\section{Conflict of Interests}

Authors declare that they have no conflict of interests.

\section{Ethical Issues}

The informed consent form was confirmed by the Ethics Commission of the Midwifery Program and authorized by the Director of $\mathrm{MoH}$ Health Polytechnic of Tanjung Karang, Lampung, Indonesia through a decree No: LB.01.02/11/0117/ 2017.

\section{Acknowledgments}

The authors are grateful for the Research Grant from the Board for the Development and Empowerment Human Resource of Health, the Ministry of the Health Republic of Indonesia.

\section{References}

1. Analen C. Saving mother's lives in rural Indonesia. Bull World Health Organ. 2007;85(10):740-741. doi:10.2471/ BLT.07.031007

2. Rahayu HSE. Mother's experience in managing labor pain in central java Indonesia. Int J Res Med Sci. 2017;5(7):30123017. doi:10.18203/2320-6012.ijrms20172979

3. Statistics Indonesia (Badan Pusat Statistik-BPS), National Population and Family Planning Board (BKKBN), and Kementerian Kesehatan (Kemenkes-MOH), and ICF International. 2013. Indonesia Demographic and Health Survey 2012. Jakarta, Indonesia: BPS, BKKBN, Kemenkes, and ICF International; 2012. https://dhsprogram.com/ pubs/pdf/fr275/fr275.pdf.

4. Nystedt A, Hildingsson I. Diverse definitions of prolonged labour and its consequences with sometimes subsequent inappropriate treatment. BMC Pregnancy Childbirth. 2014;14:233. doi:10.1186/1471-2393-14-233

5. Nyfløt LT, Stray-Pedersen B, Forsén L, Vangen S. Duration of labor and the risk of severe postpartum hemorrhage: A case-control study. PLoS One. 2017;12(4):e0175306. doi:10.1371/journal.pone.0175306

6. Li WH, Zhang HY, Ling Y, Jin S. Effect of prolonged second stage of labor on maternal and neonatal outcomes. Asian Pac J Trop Med. 2011;4(5):409-411. doi:10.1016/s19957645(11)60114-4

7. Ali A, Masakhwe BA. WHO midwifery education module 3: Managing prolonged and obstructed labour. Paper presented at: Training Course in Sexual and Reproductive Health Research 2010. Geneva Foundation for Medical Education and Research; 2010 Jul 18. http://www.gfmer. ch/SRH-Course-2010/assignments/Managing-prolongedobstructed-labour-Ali-Masakhwe-2010.htm.

8. Guidelines for Maternal Care in South Africa: A manual for clinics, community health centres and district hospitals. National Department of Health, Republic of South Africa. https://www.health-e.org.za/wp-content/uploads/2015/11/ Maternal-Care-Guidelines-2015_FINAL-21.7.15.pdf.

9. Ronsmans C, Achadi E, Cohen S, Zazri A. Women's recall of obstetric complications in south Kalimantan, Indonesia. Stud Fam Plann. 1997;28(3):203-214.

10. Yohanna WS. Analisis Faktor-Faktor yang Berhubungan dengan Persalinan Lama. J Aisyah. 2016;1(1):33-46.

11. Sutton J, Scott P. Understanding and teaching optimal foetal positioning. 2nd ed. Tauranga, New Zealand: Birth Concepts; 1996. p. 69.

12. Guittier MJ, Othenin-Girard V, Irion O, Boulvain M. Maternal positioning to correct occipito-posterior fetal position in labour: a randomised controlled trial. BMC Pregnancy Childbirth. 2014;14(1):83. doi:10.1186/14712393-14-83

13. May LE. Effects of Maternal Exercise on Labor and Delivery. In: May LE, ed. Physiology of Prenatal Exercise and Fetal Development. Boston, MA: Springer; 2012. doi:10.1007/978-1-4614-3408-5_2.

14. Hau WL, Tsang SL, Kwan W, et al. The use of birth ball as a method of pain management in labour. Hong Kong J Gynaecol Obstet Midwifery. 2012;12(1):63-68.

15. Leung RW, Li JF, Leung MK, et al. Efficacy of birth ball exercises on labour pain management. Hong Kong Med J. 2013;19(5):393-399. doi:10.12809/hkmj133921

16. Mirzakhani K, Hejazinia Z, Golmakani N, Sardar MA, Shakeri MT. The effect of birth ball exercises during pregnancy on mode of delivery in primiparous women. J Midwifery Reproductive Health. 2015;3(1):269-275. doi:10.22038/jmrh.2015.3562

17. Zaky NH. Effect of pelvic rocking exercise using sitting position on birth ball during the first stage of labor on its progress. IOSR Journal of Nursing and Health Science. 2016;5(4):19-27. doi:10.9790/1959-0504031927

18. Zimmerman E, Woolf SH. Understanding the relationship between education and health (Discussion Paper). Washington, DC: Institute of Medicine; 2014.

19. Blankfield A. The value of exercises in obstetrics. Aust J Physiother. 1966;12(2):51-54. doi:10.1016/S00049514(14)60960-0

20. Hammer RL, Perkins J, Parr R. Exercise during the childbearing year. J Perinat Educ. 2000;9(1):1-14. doi:10.1624/105812400x87455

21. Cardini F, Weixin H. Moxibustion for correction of breech presentation: a randomized controlled trial. Jama. 
1998;280(18):1580-1584. doi:10.1001/jama.280.18.1580

22. Zhang $\mathrm{QH}$, Yue JH, Liu M, et al. Moxibustion for the correction of nonvertex presentation: a systematic review and meta-analysis of randomized controlled trials. Evid Based Complement Alternat Med. 2013;2013:241027. doi:10.1155/2013/241027

23. Elkheshen SA, Mohamed HS, Abdelgawad HA. The Effect of Practicing Pelvic Rocking Exercise on Lowering Disability Level through Decreasing Pregnancy Related Lower Back Pain. J Am Sci. 2016;12(5):98-103. doi:10.7537/ marsjas12051612

24. James S, Hudek M. Experiences of South African multiparous labouring women using the birthing ball to encourage vaginal births. Health SA Gesondheid.
2017;22:36-42. doi:10.1016/j.hsag.2016.08.004

25. Garland M. Physical activity during pregnancy: a prescription for improved perinatal outcomes. J Nurse Pract. 2017;13(1):54-58. doi:10.1016/j.nurpra.2016.07.005

26. Stefani L, Mascherini G, Galanti G. Indications to Promote Physical Activity during Pregnancy. J Funct Morphol Kinesiol. 2017;2(3):31. doi:10.3390/jfmk2030031

27. Di Mascio D, Magro-Malosso ER, Saccone G, Marhefka GD, Berghella V. Exercise during pregnancy in normalweight women and risk of preterm birth: a systematic review and meta-analysis of randomized controlled trials. Am J Obstet Gynecol. 2016;215(5):561-571. doi:10.1016/j. ajog.2016.06.014

(C) 2019 The Author (s); This is an open-access article distributed under the terms of the Creative Commons Attribution License (http://creativecommons.org/licenses/by/4.0), which permits unrestricted use, distribution, and reproduction in any medium, provided the original work is properly cited. 